\title{
Análise Custo-Benefício do Uso do BIM na Obra do Complexo Prisional de Araçoiaba
}

\author{
Cost-Benefit Analysis on the use of BIM in the Construction of the Complex Prison in Araçoiaba
}

Análisis de costo-beneficio del uso de BIM en la construcción del Complejo Penitenciario de

Araçoiaba

Recebido: 01/12/2021 | Revisado: 09/12/2021 | Aceito: 13/12/2021 | Publicado: 20/12/2021

Beatriz Carneiro Menezes Silva

ORCID: https://orcid.org/0000-0002-2990-1553

Universidade Federal de Pernambuco, Brasil

E-mail: beatrizc_menezes@hotmail.com

Gabriela Torres Gonçalves

ORCID: https://orcid.org/0000-0001-6481-0609

Universidade Federal de Pernambuco, Brasil

E-mail: gabrielat47@gmail.com

Paulo de Araújo Régis

ORCID: https://orcid.org/0000-0001-7539-4890

Universidade Federal de Pernambuco, Brasil

E-mail: paulo.regis@ufpe.br

Rachel Perez Palha

ORCID: https://orcid.org/0000-0002-4424-4184

Universidade Federal de Pernambuco, Brasil

E-mail: rachel.palha@ufpe.br

\begin{abstract}
Resumo
Atualmente, é comum ter custos com retrabalho durante o processo de construção. Isto pode ser atribuído a problemas nos processos de coordenação entre as diferentes tipologias de projetos, assim como problemas no treinamento dos profissionais na área. Neste contexto, o presente estudo tem como objetivo demonstrar e avaliar o uso de ferramentas de detecção de conflitos associadas às plataformas BIM (Building Information Modeling) através da análise dos relatórios de conflito e coordenação do modelo o mais próximo possível da construção. BIM é um processo para gerar e gerenciar dados de construção que possui ferramentas, plataformas e ambientes para otimizar e automatizar o processo de detecção de conflitos entre diferentes projetos. Assim, foi realizado um estudo de caso para verificar os benefícios trazidos pelo uso da ferramenta de detecção de conflitos no gerenciamento da construção do Complexo Prisional de Araçoiaba. A metodologia utilizada consistiu na análise de vinte Relatório de Análise Crítica desenvolvidos pela empresa responsável pela Gerenciadora deste projeto. O principal objetivo do estudo de caso foi verificar o custo necessário para resolver os conflitos identificados e realizar uma análise custo-benefício. Os resultados confirmaram as vantagens associadas à verificação de conflitos entre diferentes disciplinas de projetos usando o modelo BIM.
\end{abstract}

Palavras-chave: BIM; Detecção de conflitos; Building information modelling; Gestão de projetos.

\begin{abstract}
Nowadays, it's usual to have costs with rework during the construction process. This can be attributed to problems regarding the coordination across disciplines in a project, and due to problems regarding untrained professionals. In this context, the present study aims to demonstrate and evaluate the use of clash detection tools associated with BIM (Building Information Modeling) Platforms to analyze clash reports and coordinate the model as close to construction as possible. BIM is a process to generate and manage building data that has tools, platforms, and environments to optimize and automatize the process of conflict detections among different projects. Based on this, a case study was conducted in order to verify the benefits brought with the use of the clash detection tool in the management of the construction of the Araçoiaba Prison Complex developed by the coordinator of the construction of this project. The methodology utilized consisted of the analysis of twenty Critical Analysis Report. The main goal of the case study was to verify the cost needed to solve the identified conflicts to run a benefit-cost analysis. The results of the study confirmed the advantages associated with verifying conflicts across disciplines in projects by using BIM Technology.
\end{abstract}

Keywords: BIM; Clash detection; Building information modelling; Project management.

\section{Resumen}

Actualmente, es común tener costos de reelaboración durante el proceso de construcción. Esto se puede atribuir a problemas en los procesos de coordinación entre diferentes tipos de proyectos, así como problemas en la formación de profesionales en el área. En este contexto, este estudio tiene como objetivo demostrar y evaluar el uso de herramientas de detección de conflictos asociadas a las plataformas BIM (Building Information Modeling) a través del análisis de informes de conflictos y la coordinación de modelos lo más cerca posible de la construcción. BIM es un proceso de 
generación y gestión de datos de construcción que cuenta con herramientas, plataformas y entornos para optimizar y automatizar el proceso de detección de conflictos entre diferentes proyectos. Así, se realizó un estudio de caso para verificar los beneficios que reporta el uso de la herramienta de detección de conflictos en la gestión de la construcción del Complejo Penitenciario de Araçoiaba. La metodología utilizada consistió en el análisis de veinte Informes de Análisis Crítico desarrollados por la empresa responsable para la coordinación de este proyecto. El objetivo principal del estudio de caso fue verificar el costo necesario para resolver los conflictos identificados y realizar un análisis de costo-beneficio. Los resultados confirmaron las ventajas asociadas con la verificación de conflictos entre diferentes disciplinas de diseño utilizando el modelo BIM.

Palabras clave: BIM; Detección de conflictos; Building information modelling; Gestión de proyectos.

\section{Introdução}

O sistema carcerário brasileiro vive uma grande crise que atinge todos os Estados da União: em 2015 já apresentava aproximadamente 69,2\% de superlotação (Velasco, D’Agostino, \& Reis, 2017). No que tange ao estado de Pernambuco, a partir da criação do Programa Pacto pela Vida, houve um acréscimo na quantidade de detenções, aumentando sua população carcerária (Barrocal \& Pellegrini, 2015). Desta forma, o sistema prisional do estado não acompanhou tal crescimento, piorando as questões referentes a superlotação.

A fim de mitigar o déficit carcerário em Pernambuco, através de uma parceria entre o Governo Federal e o Governo do Estado de Pernambuco, foi proposta a construção do Complexo Prisional de Araçoiaba. Este complexo prisional é composto por sete unidades prisionais, das quais cinco são destinadas a população carcerária masculina, com 388 vagas cada, e duas unidades são destinadas a população carcerária feminina, com 407 vagas cada (SDSCJ, 2014).

Devido à baixa quantidade de recursos é imprescindível que o gerenciamento deste projeto seja realizado da melhor forma possível. Para tanto, uma Gerenciadora foi contratada a fim de implementar a Modelagem da Informação para Construção ou Building Information Modeling (BIM) para melhorar o processo de gerenciamento e reduzir os custos com horas paradas e retrabalhos, que são típicos da fase de construção, através da compatibilização de projetos.

Em diversos setores da indústria, o detalhamento e a acurácia dos projetos a serem desenvolvidos apresentam fundamental importância na qualidade e atendimento aos prazos estipulados. Assim, a compatibilização de projetos, atrelada a outras ferramentas, torna-se imprescindível para a redução de custos e desenvolvimento de obras com a qualidade necessária no setor da construção civil (Coutinho, Moura, \& Teixeira, 2021). Diversos profissionais de projetos se envolvem nas etapas de execução do empreendimento, resultando em um maior entendimento das etapas construtivas e, desse modo, permitindo a “elaboração de projetos futuros com redução de incertezas, pela maior proximidade com a realidade produtiva" (Novaes, 2001).

O BIM pode ser definido como um processo integrado, que armazena e agiliza a troca de informações de projetos, criando um modelo virtual para tomadas de decisão nas diversas fases do empreendimento (Sacks, Eastman, Lee, \& Teicholz, 2018). O uso da ferramenta de detecção de conflitos ou compatibilização de projetos é um dos benefícios percebidos no BIM, mesmo nos casos em que dados não geométricos fazem parte do modelo (Selçuk Çıdık, Boyd, \& Thurairajah, 2017).

A análise custo-benefício é uma ferramenta analítica que traz ao problema informações quantitativas de modo a comparar os custos referentes ao processo planejado de intervenção com seus benefícios (Mechler, 2016). Este tipo de análise pode ser utilizada não apenas para verificar a aplicabilidade de uma ferramenta de gerenciamento, como também em outros tipos de análises, como gerenciamento de riscos em desastres naturais (Mechler, 2016), mitigação de riscos causados por terremotos em pontes e túneis (Bana e Costa, Oliveira, \& Vieira, 2008) ou modelagem de portfólio de projetos considerando informação parcial (Liesiö, Mild, \& Salo, 2008).

O processo de implementação do BIM é com frequência liderado pelo proprietário, que precisa realizar investimentos extras na contratação de equipes e profissionais com conhecimento neste processo (Sacks et al., 2018). Essa parte interessada precisa de informações que deem respaldo a este investimento, entretanto, os autores deste trabalho não conseguiram encontrar 
na literatura uma pesquisa que tenha quantificado as reduções em termos de custo que seriam provenientes da compatibilização de projetos.

Diante da lacuna encontrada na literatura, este artigo busca quantificar através de um estudo de caso na obra do Complexo Prisional de Araçoiaba os custos que incorreriam caso o projeto não fosse compatibilizado na fase pre-construção. Assim, as contribuições deste artigo consistem em uma análise custo-benefício para avaliar o uso de ferramentas BIM para compatibilização de projetos antes do início da execução do projeto, com ênfase na redução de custos acarretada pelo uso das ferramentas de detecção de conflitos quando as mesmas são utilizadas em etapas prévias a execução de uma obra. Apesar da atividade de detecção de conflitos ser realizada por muitas das organizações que já utilizam BIM, os autores não encontraram um trabalho que pudesse quantificar o impacto dessa prática se comparado ao desenvolvimento de projetos tradicional. Desta forma, este trabalho contribui com a literatura da área ao apresentar uma análise custo-benefício para quantificar os custos necessários para desenvolvimento da análise usando um modelo federado e comparar estes com os benefícios financeiros advindos do uso do BIM durante a fase de desenvolvimento de projetos. Outra contribuição do trabalho consiste no uso de um projeto real, o que permite considerar aspectos que não necessariamente seriam observados num estudo teórico, baseado apenas na percepção ou experiência dos autores. Por fim, as implicações gerenciais e práticas do estudo permitiram uma reflexão sobre o conhecimento existente, dando subsídios para avanços no estado da arte. Este tipo de análise é de grande importância por confirmar a percepção dos praticantes da área no que tange aos seus impactos do ponto de vista prático, aliando a academia ao setor industrial.

Este artigo encontra-se dividido em cinco seções, iniciando com a Introdução. A Segunda Seção apresenta um referencial teórico. A Terceira Seção apresenta a metodologia utilizada e as Seções Quatro e Cinco apresentam os Resultados e Discussões e as Conclusões, respectivamente.

\section{Referencial Teórico}

Bryde, Broquetas e Volm (2013) analisaram 35 projetos que utilizaram o BIM em diversas fases a fim de verificar quais foram os fatores de sucesso associados ao uso deste processo em projetos de construção civil, considerando nove critérios de sucesso. Eles perceberam através desta análise que $60 \%$ dos projetos identificaram como benefício a redução dos custos no projeto, aproximadamente 35\% reportaram redução no prazo, melhoria na coordenação do projeto e/ou melhoria no controle de qualidade e $37 \%$ reconheceram uma melhoria no processo de comunicação, entre outros critérios. Desta forma, é possível perceber que os benefícios do BIM são inúmeros e são percebidos pelas partes interessadas, entretanto, Bryde, Broquetas e Volm (2013) afirmaram que uma análise custo-benefício seria um fator impulsionador do uso do BIM, uma vez que poderia auxiliar a convencer os profissionais da área dos benefícios relacionados a implantação deste processo e suas ferramentas.

Mesároš e Mandičák (2017) analisaram os benefícios do BIM em projetos na Eslováquia e também verificaram que a redução de custo foi um benefício percebido por $89 \%$ dos respondentes ao questionário utilizado em seu estudo. Por outro lado, o processo de implantação do BIM não é simples. Hamdi e Leite (2014), através de um processo de entrevistas com especialistas, verificaram que existem dois grupos de riscos e desafios relacionados a implantação do BIM: relacionados a questões contratuais e questões relacionadas aos propósitos dos clientes. Como resultado desta pesquisa, os autores verificaram que os especialistas indicaram que os custos estão associados não apenas a aquisição de aplicativos e treinamento de pessoal, mas também ao investimento em infraestrutura. Desta forma, Oesterreich e Teuteberg (2018) propuseram um framework para guiar a análise custo-benefício no nível coorporativo de uma organização para os projetos que tenham implantado o BIM. A ideia dos autores foi entender os efeitos econômicos que a implantação do BIM pode ter em uma organização. Desta forma, o framework proposto não visa realizar uma análise custo-benefício em projetos, mas verificar seus efeitos do ponto de vista organizacional. 
Os benefícios do BIM são inúmeros. Além da compatibilização de projetos, o BIM também auxilia na análise de cronograma, facilita a comunicação entre as partes, aumenta a sinergia da equipe (Carmona, Carvalho, Carmona, \& Carvalho, 2017), além de melhorar a precisão dos orçamentos (Santos \& Piacente, 2021), o que é uma preocupação especialmente no que tange à obras públicas (Santos, Piacente, Neves, \& Azevedo, 2021). Abd e Khamees (2017) verificaram que os modelos BIM possuem uma taxa de erro de 7,17\% quando comparados aos as builts, enquanto que os métodos tradicionais de levantamento de projetos possuem uma taxa de erro de 47,33\%. É possível ainda realizar análises comparativas entre diferentes métodos construtivos de forma mais ágil, como a realizada por Machado et al. (2018).

Carmona et al. (2017) verificaram que no Distrito Federal 63\% dos entrevistados em seu estudo indicaram o uso do BIM para compatibilização de projetos e remoção de interferências, este resultado é compatível com o encontrado nos EUA, onde 64\% dos usuários de BIM alegaram utilizar este processo para detecção de interferências (Gholizadeh, Esmaeili, \& Goodrum, 2018). O produto entregue pelo BIM no que diz respeito a compatibilização de projetos vai além do que é entregue tradicionalmente neste processo, pois permite a construção virtual do projeto, o que auxilia na identificação de interferências e falhas com o cronograma (Dantas Filho, Barros Neto, \& Angelim, 2017). Esse resultado já havia sido identificado por Brito e Ferreira (2015), que verificaram que a adoção do BIM 4D melhora a integração e comunicação entre os envolvidos e reduz o esforço mental de visualização e interpretação, facilitando a compatibilização no nível de planejamento. Existem três problemas principais que estão associados a falhas no planejamento e controle da construção: o processo de projeto é repleto de incertezas, o processo de projeto é iterativo entre diversos projetistas e o trabalho em projetos expande com a disponibilidade de tempo (Wesz, Formoso, \& Tzortzopoulos, 2018).

A compatibilização de projetos é um dos produtos resultantes do segundo estágio de adoção do BIM, quando se começa o processo de interação, ainda que assíncrono (Ruschel, Andrade, \& Morais, 2013). Esses problemas acontecem devido ao trabalho isolado os projetistas, especialmente no que tange aos projetos de instalações prediais e devido ao uso de sistemas de nuvem que incentivam esses profissionais a trabalharem isoladamente (Akponeware \& Adamu, 2017).

Os conflitos ocorrem em sua grande maioria devido à grande variedade de disciplinas que compõem a gama de projetos necessários a construção de uma edificação. Quando todos os modelos são superpostos, há sempre interferências entre um ou outro, que podem ser detectadas na fase de obras, ou ainda na fase de projetos, se utilizada as ferramentas pertinentes. Existem três tipos conhecidos de conflitos encontrados: hard clash, soft clash e logical clash. A primeira trata de conflitos causados por objetos que ocupam o mesmo espaço, a segunda quando os componentes de construção estão próximos demais para permitir manuseio e a última quando um componente pode interferir no processo construtivo de outro componente, sem propriamente ocupar o mesmo espaço (Sacks et al., 2018).

Uma vez que o processo de projeto de uma construção envolve múltiplos projetistas a compatibilização de projetos é extremamente importante para afastar a possibilidade de problemas futuros em termos de aumento de custos por retrabalho ou horas paradas. Essa responsabilidade é atribuída de uma forma geral aos coordenadores BIM ou empresas gerenciadoras e a atividade de detecção de interferências inclui o processo de integração, identificação e proposição de soluções (Jacobsson \& Merschbrock, 2018).

Os modelos podem ser compartilhados de duas formas: utilizando uma plataforma BIM única para abrir e gerenciar os modelos de cada disciplina ou usando um modelo federado, o qual permite importar os modelos específicos de cada disciplina para uma ferramenta BIM de integração específica, como é o caso do Naviswork e VICO Office (Sacks et al., 2018). Entretanto, os softwares que fazem identificação de interferências em modelos federados não fazem esta análise automaticamente, de modo que os gerenciadores do modelo precisam realizar esta análise e classificar os tipos de interferências antes de sua mitigação, gerando custos ao processo (Pärn, Edwards, \& Sing, 2018). Um outro problema é que com frequência os membros da equipe não trabalham de forma proativa para evitar as interferências, posicionando-se apenas de forma reativa (Pärn et al., 2018). 
Apesar de todos os estudos sobre a detecção de conflitos usando BIM, não foram realizados em nenhum destes artigos um levantamento de quantitativo em determinados tipos de projeto que pudesse subsidiar as afirmações que o BIM é capaz de reduzir custos na construção civil e que a mais elementar destas reduções acontece devido à detecção de conflitos. Esses percentuais e valores absolutos variam de projeto para projeto, assim como os custos com seu processo de implementação, mas é importante que para disseminação e uso deste processo existam levantamentos quantitativos neste sentido. Assim, neste artigo, foi utilizado um estudo de caso para fazer uma análise custo-benefício do uso do BIM e apontar em que direção esses investimentos podem garantir uma redução de custo no processo como um todo.

\section{Metodologia}

Este trabalho foi desenvolvido através da metodologia de estudo de caso (Yin, 2014) que é uma metodologia amplamente aceita na área de construção civil. A fim de desenvolver este estudo, foi utilizada uma abordagem em fases para melhor entender o problema, assim como acontece em diversas abordagens, tais como o modelo de racionalidade de Simon (1982) e a abordagem construtivista (Berkes \& Davidson-Hunt, 2007). Desta forma, foram identificadas em consonância com as etapas sugeridas por Kasanen, Lukka e Siitonen (2007), cinco etapas para desenvolvimento desta pesquisa. Estas fases estão divididas em: (1) Revisão da literatura ao longo de todo o período do estudo; (2) Compreensão do problema real; (3) Desenvolvimento da metodologia a ser aplicada; (4) Implementação da metodologia e refinamento; (5) Análise dos resultados encontrados e reflexão frente a literatura.

\subsection{Etapa de Compreensão do problema real}

No início do contrato estabelecido com a empresa Gerenciadora contratada para gerenciar o desenvolvimento dos projetos e construção do Complexo Prisional de Araçoiaba utilizando o processo BIM foi identificado que um dos desafios da equipe seria melhorar o processo de gerenciamento de projetos e reduzir os custos com horas paradas e retrabalhos, que são típicos da fase de construção, através da compatibilização de projetos. Quando finalizada a construção, o Complexo Prisional de Araçoiaba deverá ser composto por sete unidades prisionais, sendo cinco unidades masculinas e duas femininas (SDSCJ, 2014). Quando em pleno funcionamento, ofertará 2754 vagas ao sistema penitenciário de Pernambuco. A obra foi orçada inicialmente em aproximadamente $\mathrm{R} \$ 130.000 .000,00$, dispostos entre as sete unidades prisionais, com custo médio de $\mathrm{R} \$ 18.500 .000,00$ por unidade.

Uma das entregas realizadas pela empresa durante a execução do gerenciamento e supervisão das obras no Complexo Prisional são os Relatórios de Análise Crítica (RACs). O documento compila as interferências e incompatibilidades encontradas entre os projetos de tipologias distintas, trazendo as informações necessárias para a compatibilização dos projetos de cada uma das sete unidades prisionais que o compõem. Na Figura 1 apresenta-se o modelo dos RACs.

Desta forma, foi percebido que seria importante verificar quais seriam os reais ganhos provenientes deste produto entregue ao cliente. Neste projeto, estes custos seriam de responsabilidade do Poder Público, cliente do projeto, porque a construção desta obra foi realizada através da Lei das Licitações e os projetos eram de responsabilidade da contratante, assim, quaisquer que fossem os erros encontrados durante a execução do projeto e que onerassem o custo da obra, seriam repassados através de aditivos para o contratante, não sendo assumidos de nenhuma forma pela construtora, pela gerenciadora ou pelos projetistas.

Assim, o estudo de caso apresentado consiste na quantificação dos custos finais que seriam incorridos no projeto, caso a compatibilização de projetos não houvesse acontecido. Os custos que se esperava encontrar no levantamento seriam aqueles acarretados por conflitos entre tipologias de projeto, que gerariam gastos com retrabalho, no caso da possibilidade de resolução do conflito em obra, e/ou ócio de equipe, enquanto a solução para a interferência é buscada pelos projetistas responsáveis. 
Figura 1 - Exemplo de RAC.

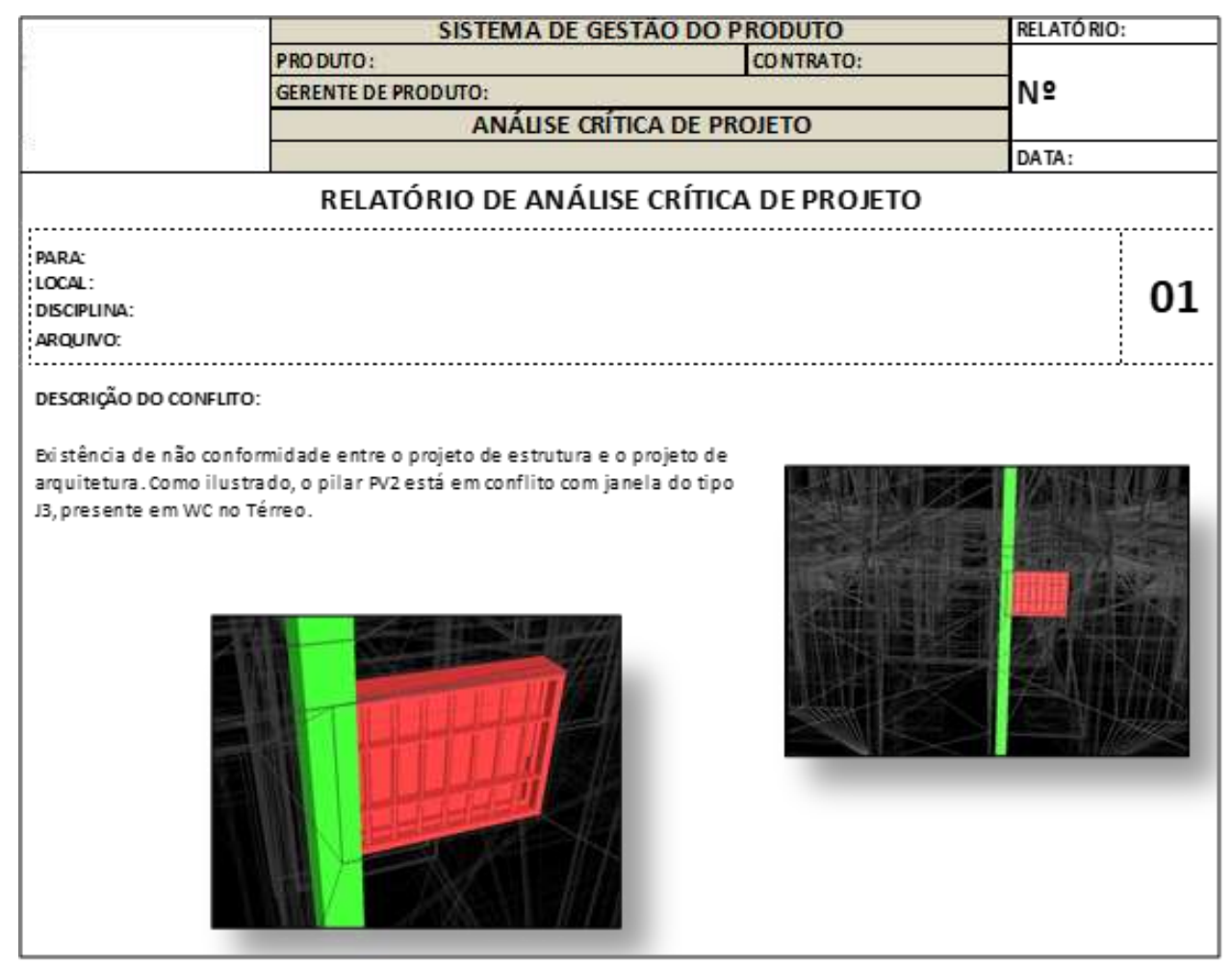

Fonte: Autores (2021).

\subsection{Etapa de Desenvolvimento da metodologia aplicada}

A partir da análise dos RACs, foi elaborada uma planilha com o resumo de todas as interferências encontradas, de forma a quantificar os conflitos, para identificação da tipologia construtiva com maior número de interferências. A partir desta informação, as interferências foram classificadas como apresentado no Quadro 1.

Enquadram-se como "Solucionável em obra - sem custo" aquelas interferências que são solucionáveis em obra sem custo adicional. Um exemplo deste seria o conflito entre o cabeamento flexível que atravessa uma viga na vertical, pois é possível desviar os cabos sem perfurar a viga, sendo solucionado sem custo adicional. Em "Solucionável em obra - com custo", enquadram-se os conflitos que podem ser solucionados em obra, mas com aumento de custos. Por exemplo: as tubulações de água fria que atravessam vigas horizontalmente, onde se faz necessária a perfuração dos elementos estruturais em questão para permitir a passagem dos tubos.

Quadro 1 - Classificação das interferências.

\begin{tabular}{|l|l|}
\hline Classificação da Interferência & Definição \\
\hline Solucionável em obra - sem custo & O conflito é solucionável em obra, sem custos adicionais. \\
\hline Solucionável em obra - com custo & O conflito é solucionável em obra, com custos adicionais. \\
\hline Revisão de projeto & $\begin{array}{l}\text { O conflito de difícil solução em obra, sendo necessária } \\
\text { revisão dos projetos. }\end{array}$ \\
\hline $\begin{array}{l}\text { Revisão de projeto com custo de } \\
\text { solução }\end{array}$ & $\begin{array}{l}\text { O conflito de difícil solução em obra cuja revisão de } \\
\text { projeto acarretará em custos com material. }\end{array}$ \\
\hline
\end{tabular}

Fonte: Autores (2021). 
Enquadram-se em "Revisão de projeto" os casos em que seria inviável a resolução do problema em obra, tornando-se necessária a revisão dos projetos por parte dos projetistas para continuação dos serviços. Nesse caso, foi quantificado o custo incorrido pelas horas paradas referente às equipes de execução dos serviços afetados pela incompatibilidade durante o período necessário para solução proveniente do projetista. Exemplos desse tipo de interferência seriam as janelas que cortam elementos estruturais, assim como as portas que ultrapassam os limites das vigas.

Foram classificados como "Revisão de projeto com custo de solução", os casos em que seria inviável a resolução do problema dentro do canteiro de obras, tornando-se necessária a revisão dos projetos por parte dos projetistas para continuação dos serviços e cujas soluções óbvias incluem custos adicionais com materiais. Enquadram-se nessa situação as tubulações de água fria, esgoto e combate a incêndio que cortam cintas e capitéis. Como exemplo de solução para estes problemas, no primeiro caso, considerou-se necessário o desvio do elemento estrutural de fundação e no caso dos capitéis, foi considerada a adição de $10 \mathrm{~cm}$ na espessura ao capitel, conforme sugerido pelo projetista da obra do Complexo Prisional de Araçoiaba.

A fim de quantificar estes custos, foi determinado que seria realizado um orçamento para a resolução dos conflitos detectados, caso estes fossem identificados durante a execução da obra. Uma vez que as sete unidades prisionais eram semelhantes em termos de custo e estrutura, foi escolhida uma unidade prisional para análise das interferências encontradas, de modo que os valores encontrados pudessem ser estendidos para as demais unidades. A Figura 2 apresenta o fluxograma do estudo de caso realizado.

As análises de levantamento de custo foram referentes às atividades de retrabalho, horas paradas e aquisição de materiais e serviços necessários à solução dos conflitos. A fim de levantar estes custos, foram considerados como:

retrabalho: atividades que seriam necessárias para demolição e construção da nova instalação após revisão do projeto custos com horas paradas ou horas ociosas: custos com as horas contabilizadas para as equipes que não poderiam trabalhar durante o processamento da solicitação de informação aos projetistas caso a interferência fosse percebida apenas durante a construção.

custos com materiais e serviços: se referem a materiais que foram adquiridos ou serviços que foram contratados, mas devido à incompatibilidade dos projetos se tornaram obsoletos.

Quando foi considerado que a resolução da interferência na fase de obra seria inviável, foram quantificados os custos com horas paradas da equipe de execução, durante o desenvolvimento da solução por parte dos projetistas. É importante perceber, ainda, que ao realizar a compatibilização dos projetos durante a fase de projeto, aumenta-se a rastreabilidade das mudanças de projeto, possibilitando a realização do As Built da obra com mais acurácia e precisão. 


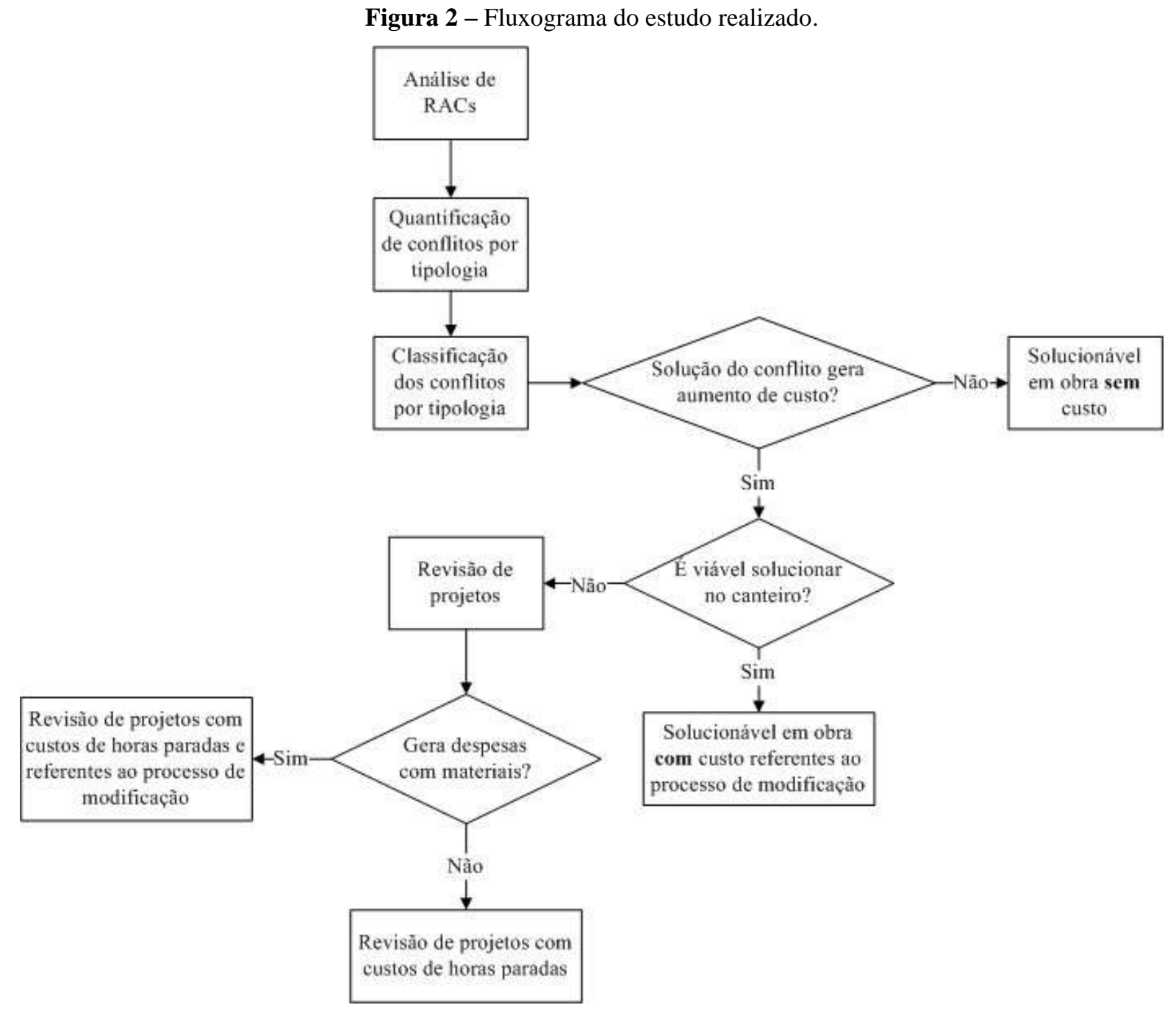

Fonte: Autores (2021).

\subsection{Etapa de Implementação e Refinamento}

A partir do levantamento realizado nos RACs, foram identificados um total de 520 conflitos, distribuídos entre 11 tipologias, sendo elas: Arquitetura, Cabeamento Estruturado, Circuito Fechado de Televisão (CFTV), Detecção e Combate a Incêndio, Instalações Elétricas, Estrutura, GLP, Sonorização, Sistema de Proteção Contra Descargas Atmosféricas (SPDA), Climatização e Instalações Hidrossanitárias (água fria, águas pluviais e esgoto sanitário), conforme Figura 3. Destas, 397 referiam-se a interferências com o subsistema estrutura. Desta forma, os estudos foram direcionados para analisar apenas os conflitos com este subsistema.

As interferências encontradas referem-se apenas a conflitos físicos entre elementos, sendo esta técnica conhecida como Hard Clash. Os conflitos entre definições e especificações geométricas de equipamentos e ambientes não foram identificados e, por isso, não foram quantificados no estudo de redução dos custos. Quanto as tipologias de projeto consideradas, foram quantificados apenas custos com interferências entre o projeto de estrutura e as diferentes tipologias, além de haverem sido desconsiderados custos devido ao efeito dominó da sequência de atividades. Sendo assim, foram considerados apenas os custos diretos associados as interferências, sem levar em consideração os atrasos e, consequentemente, custos com horas parados, gerados nos serviços dependentes da conclusão destas atividades. Além dos limitantes citados, também não foram considerados os custos acarretados com a administração da obra e instalações provisórias devido ao aumento de prazo. 
Figura 3 - Frequência de interferências por tipologia.

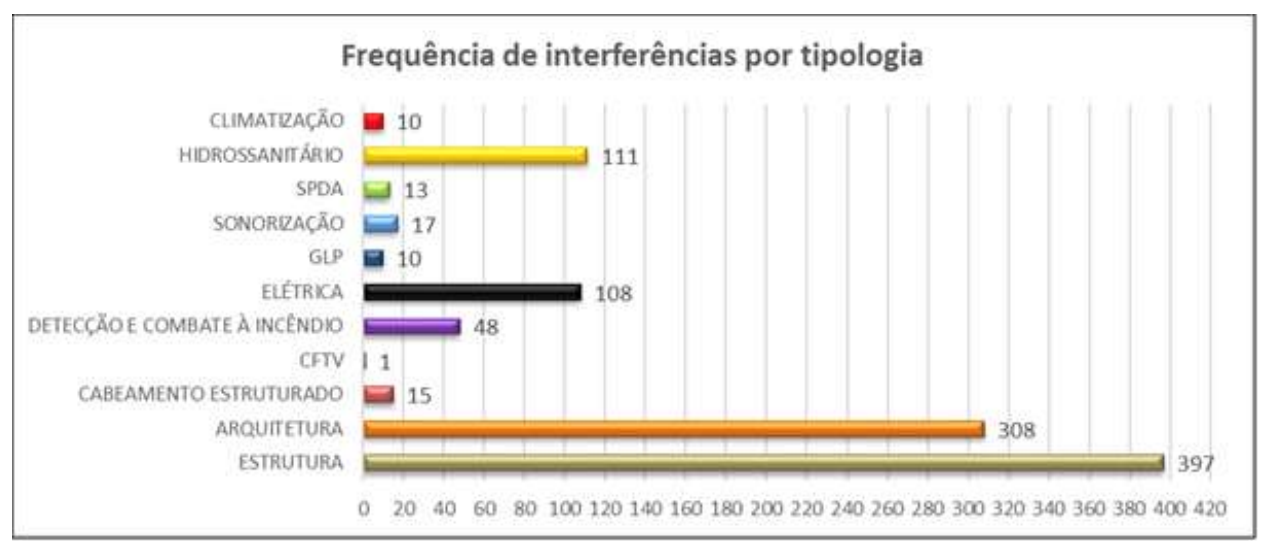

Fonte: Autores (2021).

\subsection{Etapa de Análise e Reflexão}

A fim de analisar e quantificar os benefícios do uso do BIM em uma obra contratada pelo sistema de contratação ProjetoConcorrência-Construção, foi realizada uma análise custo-benefício. Assim, é possível avaliar e quantificar as vantagens da utilização da compatibilização de projetos associada ao processo BIM, usando os dados obtidos no estudo de caso no Complexo Prisional de Araçoiaba, e ratificar alguns dos benefícios trazidos pelo uso do BIM como ferramenta no gerenciamento de projetos.

Os benefícios considerados são a redução de custos caso os conflitos não viessem a acontecer durante o período de construção da obra, ou seja, os custos provenientes do levantamento resultado da Etapa de Implementação e Refinamento. Os custos considerados na análise custo-benefício são os incorridos com a contratação da gerenciadora para implementação do processo BIM na fase de compatibilização de projetos. Foi ainda realizada uma análise comparando com a literatura os potenciais benefícios deste processo e aqueles identificados neste projeto.

\section{Resultados e Discussão}

A fim de realizar o processo analítico, foram levantados detalhadamente os conflitos encontrados envolvendo o subsistema estrutura, para verificar com quais subsistemas foram encontrados conflitos. Esta informação está apresentada na Figura 4, onde é possível perceber que aproximadamente $63 \%$ dos conflitos acontecem com a arquitetura, $16 \%$ com as instalações elétricas, $12 \%$ com as instalações hidro sanitárias e $9 \%$ com os demais subsistemas.

Das 249 interferências identificadas entre os projetos de estrutura e o de arquitetura, 242 consistiram no conflito entre pilares ou vigas, com portas e/ou janelas. No caso da segunda maior tipologia que apresenta interferências, elétrica, foi muito comum a necessidade de desvio dos elementos estruturais que estão sendo cortados por eletrodutos da rede elétrica. Entre os projetos de estrutura e instalações hidrossanitárias, o conflito mais encontrado foi o corte de elementos estruturais por tubulações de água fria e águas pluviais, gerando custos adicionais com o desvio desses tubos, quando não necessária a perfuração de vigas e pilares para a passagem da tubulação citada. 
Figura 4 - Frequência de interferências com o projeto de estrutura.

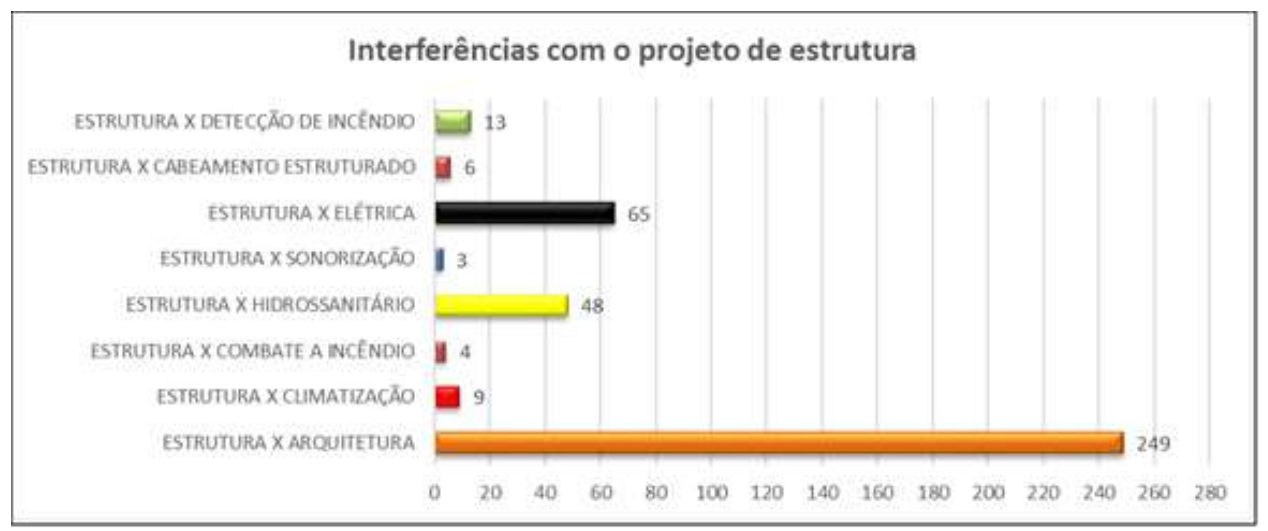

Fonte: Autores (2021).

Após a quantificação e identificação da tipologia construtiva que apresentou maior número de interferências, os conflitos encontrados foram classificados em quatro seguimentos, conforme Quadro 1. Após realizada a classificação, das 397 interferências verificadas, 80 foram enquadradas na classe 1 - Solucionável em obra sem custo (SSC), 99 foram enquadradas na classe 2 - Solucionável em obra com custo (SCC), 192 foram enquadradas na classe 3 - Revisão de projeto (RV) e 26 foram enquadradas na classe 4 - Revisão de projeto e custo com solução (RVCS), conforme Figura 5.

Figura 5 - Classificação das interferências.

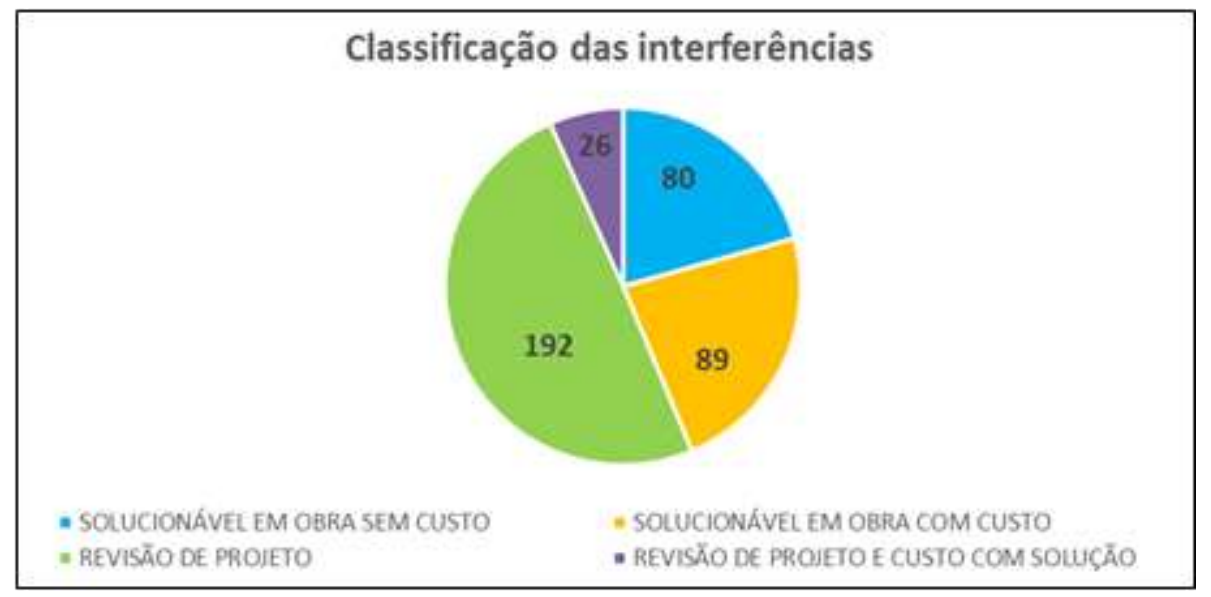

Fonte: Autores (2021).

\subsection{Conflitos solucionáveis em obra sem custo}

Os conflitos mais comuns encontrados nesta categoria foram as janelas tipo seteiras em concreto, que coincidiam em algumas áreas com vigas da edificação. A solução encontrada foi a execução da abertura no concreto apenas até a altura da viga, não onerando o custo de execução do serviço. A segunda interferência mais comum foram as portas em grades de ferro coincidindo com pilares. Neste caso, já se encontra previsto em projeto a instalação de inserts neste elemento estrutural, o que possibilita a execução das peças arquitetônicas citadas sem qualquer custo adicional. Além dos citados, foram enquadradas nessa classificação alguns desvios de cabos, eletrodutos e tubulação que atravessam elementos estruturais como vigas e cintas na vertical, bem como pilares na horizontal e vertical. Não foram incluídas as tubulações das instalações hidrossanitárias e de combate a incêndio, devido à necessidade de especificação do projetista, a fim de manter as perdas de carga calculadas. A 
relocação de elementos facilmente deslocáveis, tais como luzes de emergência e potenciômetro que estavam em conflito com vigas, lajes e/ou pilares também foram enquadradas nesta tipologia. A Figura 6 apresenta as interferências classificadas como solucionáveis em obra sem custo.

Figura 6 - Interferências classificadas como solucionáveis em obra sem custo.

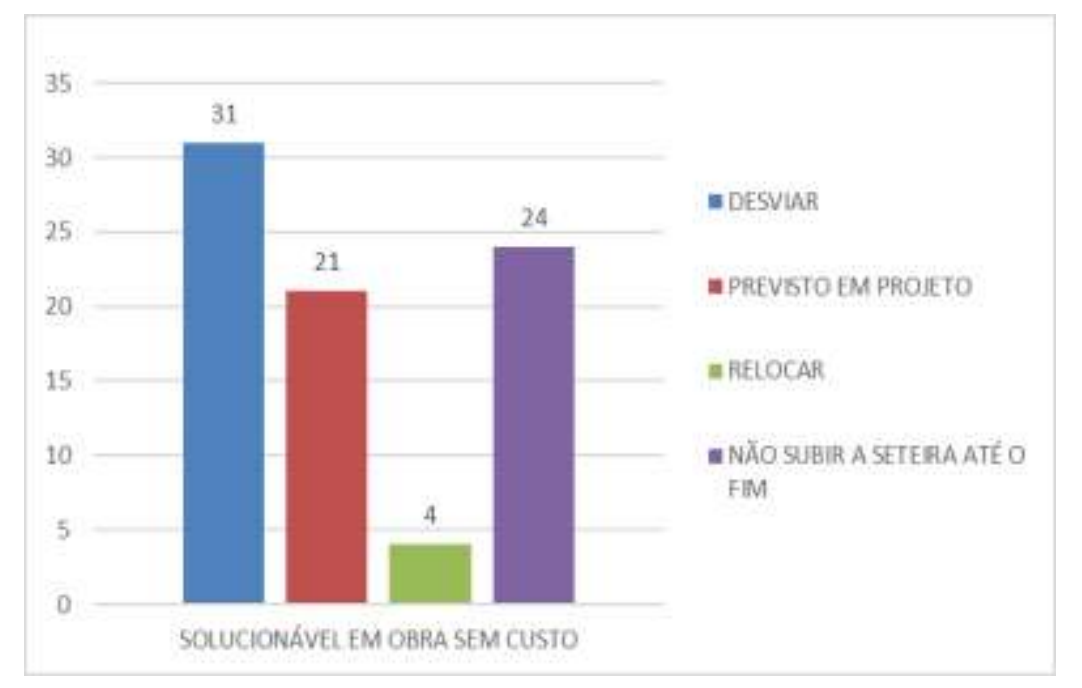

Fonte: Autores (2021).

É possível perceber que em todos os casos foram apresentadas soluções simples para estes conflitos. Apesar de não se quantificar nenhum custo, no que tange a este tipo de interferência, existem custos que não podem ser levantados antes de o problema ser encontrado na obra. Estes são custos acarretados pela improdutividade da equipe no momento em que se depara com cada um destes problemas até encontrar uma solução.

\subsection{Conflitos que geram aumento de custo}

O processo de orçamento estabelece quanto será gasto para obtenção de um determinado produto, no caso da engenharia civil, uma obra ou projeto, como também o valor a ser recebido como compensação por tal produto (Oberlender, 2014). No tocante às obras públicas, o Governo Federal, através de Decreto n ${ }^{\circ} 7.983$ de 08 de abril de 2013 estabelece que os orçamentos de obras públicas devem ter seus preços unitários retirados das tabelas referenciais de composição de serviços de engenharia do SICRO (Sistema de Custos Rodoviários)/DNIT e SINAPI (Sistema Nacional de Pesquisa de Custos de Índices da Construção Civil)/Caixa Econômica Federal. Quando não contemplados nas tabelas citadas, os serviços devem ser orçados mediante composição de preços unitárias, com valores de insumos e mão de obra retiradas das tabelas de referência (Brasil, 2013).

Desta forma, a fim de realizar os cálculos referentes aos custos incorridos pelos possíveis atrasos ocasionados pelo processo de solicitação de informação e modificação de projeto durante a construção do projeto, foram considerados os preços unitários utilizados neste estudo foram provenientes da planilha contratual da obra, proposta pela construtora vencedora da licitação. Aquelas atividades que não se encontravam contempladas nesta tabela, foram retiradas do SINAPI. Os preços unitários retirados da planilha orçamentária contratual e utilizados nesse estudo já incluem os valores de custos indiretos, através da aplicação do BDI (Benefícios e Despesas Indiretas) da obra sobre os serviços orçados. O BDI representa os gastos com administração central da empresa, custo financeiro do contrato, seguros, garantias e tributos sobre a receita, existente em todas as obras de engenharia. Além disso, os valores constantes nesta planilha, tinham como data base maio de 2014, tendo sido atualizados utilizando-se o Índice Nacional da Construção Civil (INCC). 


\subsubsection{Solucionável em obra com custo (SCC)}

Com o intuito de auxiliar no levantamento de custos associados a resolução de interferências classificadas como solucionáveis em obra com custo (SCC), estas foram analisadas quanto às ações que levariam a sua solução, no intuito de tipificar o serviço a ser orçado. Diante desta análise, foi possível obter um panorama inicial das principais ações que seriam tomadas em obra com o intuito de sanar o conflito. Os estratos de interferências encontrados nesta classe são apresentados na Figura 7.

Figura 7 - Interferências solucionáveis em obra com custo.

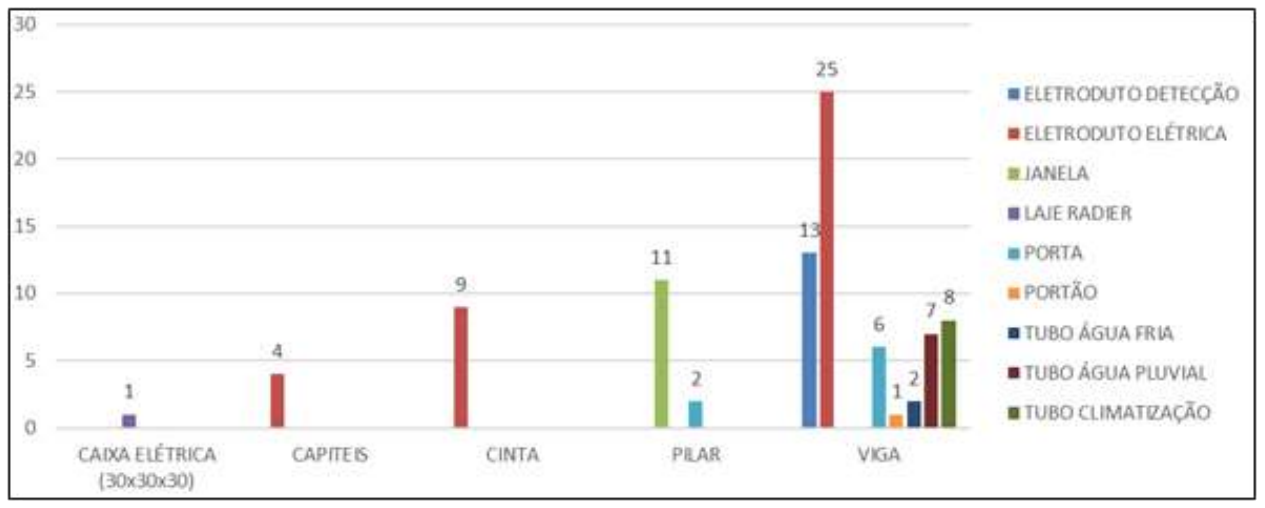

Fonte: Autores (2021).

Das 99 interferências analisadas:

- 59 são solucionadas com o desvio de eletrodutos de elétrica, deteç̧ão de incêndio e tubos de climatização que se encontram em conflito com vigas, cintas e capitéis

- 16 interferências são solucionadas através da aquisição de novas esquadrias, com dimensões diferentes das explicitadas no quadro de quantidades do projeto, devido à esquadria encontrar-se entre dois pilares, sem folga ou possibilidade de relocação, ou portas com altura superior à cota de início da viga ou com dimensões superiores ao vão de instalação.

- A terceira interferência mais comum nesta classificação trata de furos em vigas, quando a mesma é cortada por tubulação hidrossanitária ou de combate a incêndio, cujo simples desvio não é viável, devido às perdas de carga provocadas pelas curvas do desvio.

Além de outros problemas que aparecem com menor frequência. Das 99 interferências 11 previam a troca de janelas ou portas devido a outra fonte de interferência, desta forma, foram contabilizadas ações para a resolução de 88 interferências. As ações podem ser visualizadas na Figura 8.

Desta forma, foram orçados custos com a compra de novas esquadrias, fornecimento e instalação de tubos PEAD e cobre flexível, eletroduto de PVC rígido, eletroduto de alumínio e furo em elementos de concreto, que totalizaram um custo de retrabalho de $\mathrm{R}$ \$44.570,71 para solucionar estas interferências. Com a aplicação do fator de reajuste apenas nos itens provenientes da planilha contratual, foi obtido um montante de $\mathrm{R} \$ 51.857,85$ para a resolução das interferências classificadas como solucionáveis em obra com custo. 
Figura 8 - Ações encontradas para as interferências solucionáveis em obra com custo.

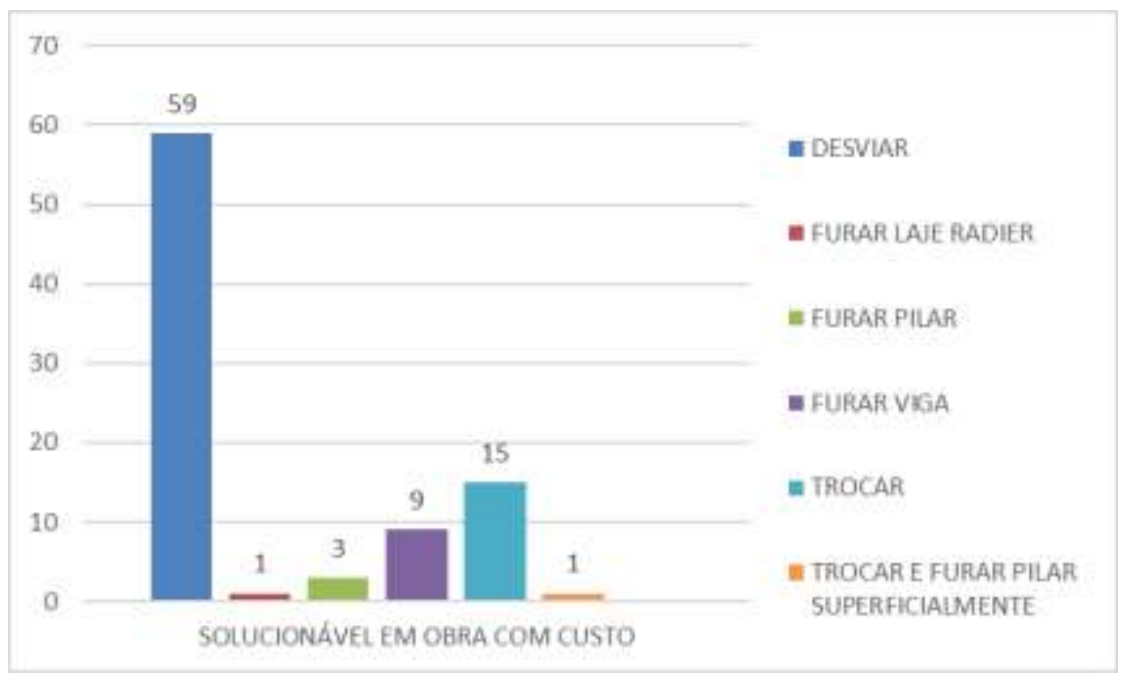

Fonte: Autores (2021).

\subsubsection{Revisão de projeto}

Conforme apresentado na Figura 5, 192 interferências foram classificadas na tipologia de Revisão de Projeto e foram distribuídas conforme Figura 9. A maioria das interferências classificadas em "Revisão de Projeto" se trataram de janelas e portas em conflito com pilares e/ou vigas. As demais ocorrências são relativas às telhas de fibrocimento do módulo grupo gerador. O telhado do grupo gerador foi projetado como se fosse um telhado inclinado, no entanto, o projeto estrutural prevê a construção de uma laje horizontal, com altura superior ao prevista para o telhado, gerando um conflito entre lajes, vigas e o telhado projetado. Também foram constatados conflitos entre uma caixa de gordura e uma sapata, exaustor e laje e paredes e vigas que foram projetadas com inclinações diferentes. Foi enquadrada nessa classificação, também, a interferência relativa a eletrodutos que cortavam uma cinta, impossibilitando o simples desvio do elemento estrutural.

Figura 9 - Interferências classificadas como necessária revisão de projeto.

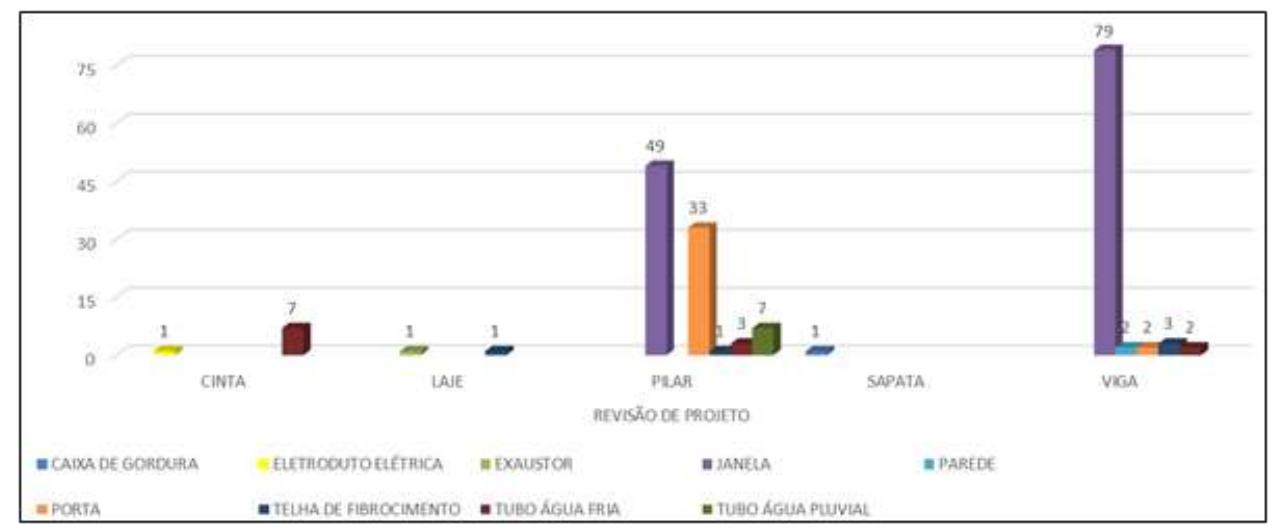

Fonte: Autores (2021).

Após a classificação de todas as interferências listadas, foram identificadas as prováveis ações a serem desenvolvidas pelos projetistas durante a revisão dos projetos, sendo elas: desviar, relocar e revisar que se encontram apresentadas na Figura 10 . 
Figura 10 - Ações encontradas para as interferências solucionáveis em obra com custo.

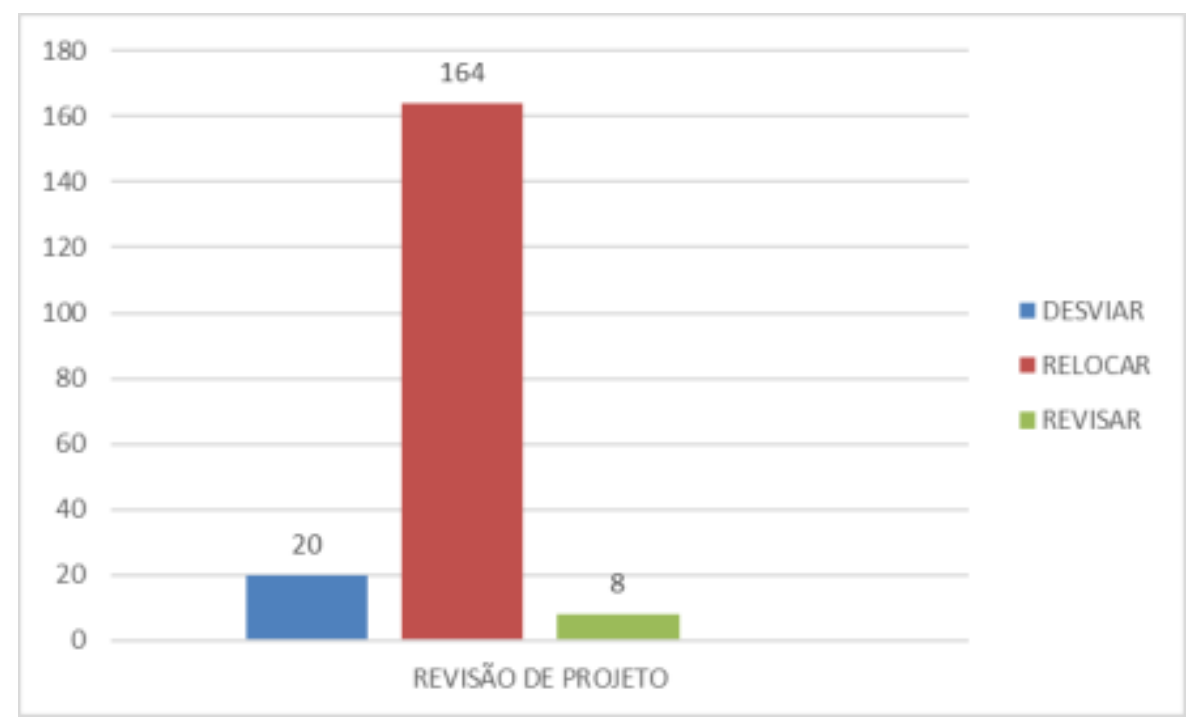

Fonte: Autores (2021).

Em diversos projetos gerenciados pela empresa responsável pela implementação do BIM na obra do Complexo Prisional de Araçoiaba e contratada para realizar as análises dos RACs usando a detecção de conflito, foi verificado empiricamente que a revisão dos projetos de forma a resolver os conflitos de um relatório de análise crítica durava cerca de 1 semana, ou seja, 44 horas uteis de trabalho. Sendo assim, as interferências objeto desse estudo foram subdivididas, de acordo com seu módulo e etapa de execução, partindo do pressuposto que aqueles projetos seriam revisados na data prevista para o início dos serviços relativos ao mesmo. A partir desta data, seriam necessárias 44 horas para a comunicação com os projetistas, revisão dos projetos e reenvio dos projetos revisados para a obra, possibilitando, então, sua continuação.

Em todos os serviços, foi considerado para cálculo a equipe necessária para realização daquela atividade dentro do prazo estipulado em cronograma. Por exemplo, se para instalar todas as esquadrias de um módulo são necessárias 70 horas do pedreiro, no entanto, só estão disponíveis 5 dias, ou seja, 44 horas, para a execução das mesmas, então são necessários 2 pedreiros para atender ao cronograma planejado. Todos os valores de preços unitários para cálculo destes serviços foram provenientes da planilha contratual, sendo assim necessário o reajuste dos valores em sua totalidade. Apesar destas atividades incluírem metodologias diferentes, todos os cálculos foram feitos considerando uma carga horária trabalhada de 44 horas semanais distribuídas ao longo dos dias úteis de trabalho da equipe, conforme apresentado no cronograma de planejamento da obra. Por fim, cabe ressaltar que foram desconsiderados os serviços impactados pelo efeito cascata, ou seja, as horas paradas das equipes que iriam realizar as atividades subsequentes e dependentes daquelas impactadas pelo conflito não foram objeto desse estudo devido à complexidade que envolve tal análise.

Em relação a estas interferências, foram orçados os custos com a improdutividade das equipes responsáveis pela execução de serviços de alvenaria por estarem paradas, que envolveu as atividades de alvenaria propriamente dita e grauteamento das paredes, serviços de instalação de esquadrias, execução de telhamento, que envolveu o telhamento e a estrutura para a instalação do telhamento, além serviços de instalação de cabos, tubos e eletrodutos para instalações hidrossanitárias, tubos de climatização e instalações elétricas, totalizando um montante de $\mathrm{R} \$ 34.807,38$. Com a aplicação do fator de reajuste, o valor atualizado foi de $\mathrm{R} \$ 41.385,98$. 


\subsubsection{Revisão de projeto com custo de solução}

No caso deste tipo de interferência, além dos custos referentes à equipe parada aguardando uma solução do projetista, ainda são contabilizados os custos adicionais para a execução da alteração do projeto, que não se encontra orçada em planilha orçamentária. Foram encontradas 26 interferências classificadas nesta tipologia e estratificadas conforme apresentado na Figura 11 .

Figura 11 - Interferências classificadas como necessária revisão de projeto e custo com solução.

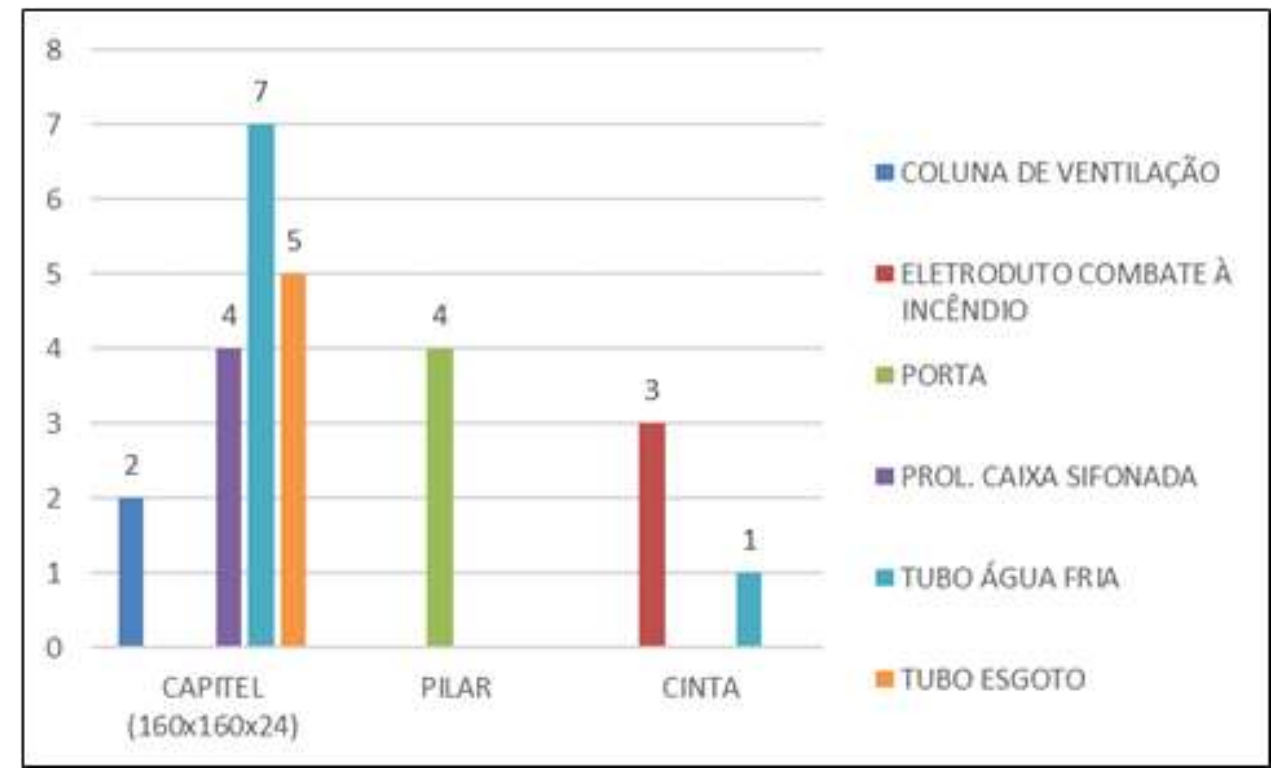

Fonte: Autores (2021).

Dentre os conflitos classificados, o mais comum foi a interferência de tubulação de água e esgoto com capiteis de vários ambientes. A solução encontrada pelo projetista foi o aumento em $10 \mathrm{~cm}$ na espessura dos capiteis, de forma a permitir a instalação das tubulações em conflito por dentro do capitel, sem gerar riscos à estrutura da edificação, acarretando um aumento do custo executivo da peça estrutural.

As demais situações enquadradas nessa tipologia de conflito foram as interferências entre as tubulações de combate a incêndio e tubos de água fria com quatro cintas. Nestes casos é necessário revisar o projeto devido à perda de carga destes elementos quando a tubulação é desviada dos elementos estruturais, pois não se recomenda perfurar as cintas. Além destes conflitos, surgiram portas que precisaram ser relocadas por estarem em conflito com os pilares, que, quando relocadas, entraram em conflitos com as pias já compradas, sendo necessária a troca desses elementos por estruturas menores, de forma a permitirem a abertura das portas sem maiores interferências.

Para solução das interferências, foram identificadas três possíveis ações a serem tomadas, que se encontram explicitadas na Figura 12. O cálculo referente às horas paradas foi realizado seguindo as mesmas premissas apresentadas na classificação anterior, enquanto que os cálculos com materiais e serviço foi realizado de acordo com as soluções apresentadas pelo projetista. 
Figura 12 - Ações a serem tomadas para resolução dos conflitos classificados como necessária revisão de projeto e custos com solução.

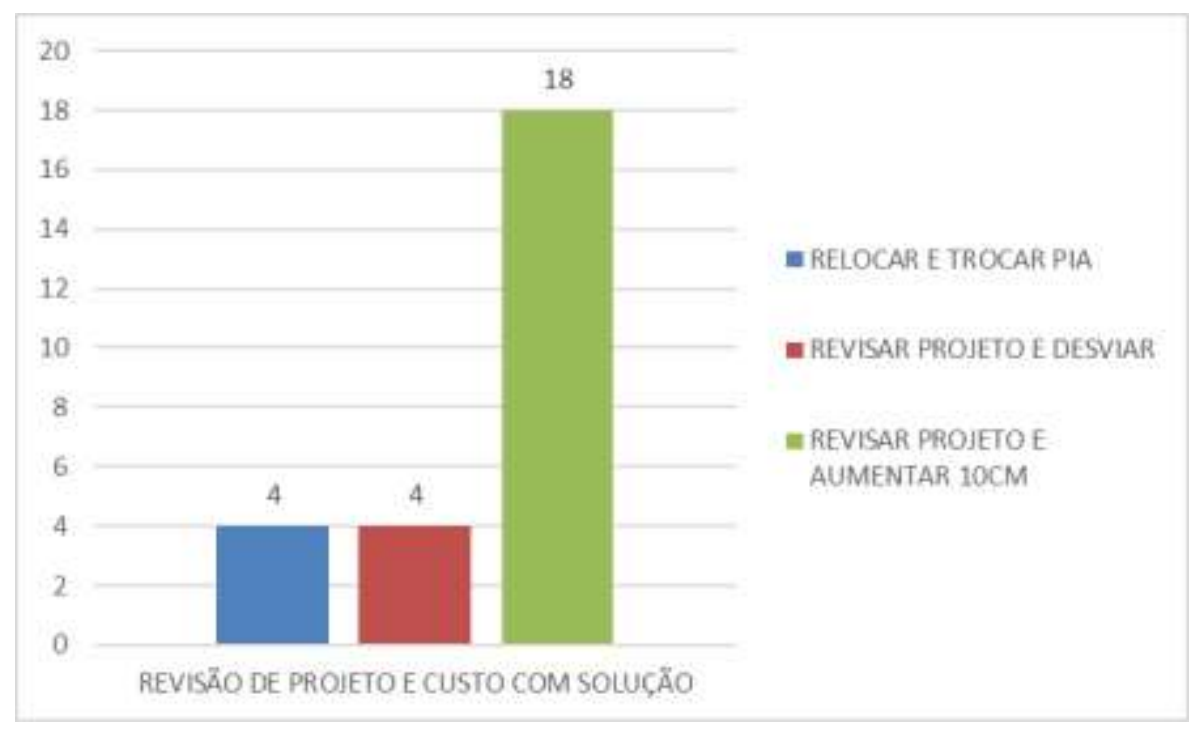

Fonte: Autores (2021).

Neste caso, precisaram ser contabilizados serviços referentes a revisão dos projetos e desvio de tubulação de água e combate ao incêndio, realocação de portas e compra de novas pias para alguns banheiros dos módulos polivalente e educacional, bem como a revisão do projeto de fundação e aumento da espessura de alguns capiteis dos módulos administração e revista, totalizando um custo de $\mathrm{R} \$ 1.848,90$ para as horas ociosas da equipe e um montante de $\mathrm{R} \$ 4.662,13$ com custos de compra e execução dos serviços necessários a efetiva resolução dos conflitos, após revisão de projeto. Após aplicação do fator de reajuste, estes custos totalizam R $\$ 7.741,61$.

\subsubsection{Análise Custo-Benefício}

O custo total estimado para correção das interferências durante o período de execução de obra pode ser visualizado na Tabela 1 e totaliza R $\$ 100.985,44$. Estes custos são evitados pelo uso do processo BIM e suas ferramentas de compatibilização de projetos durante a fase de projetos da obra. Esse valor corresponde a um percentual de $0,58 \%$ do custo de construção da Unidade Prisional Masculina 01 do Complexo Prisional de Araçoiaba e 1,4\% do custo total da estrutura da mesma unidade prisional. Logo, infere-se que, para a construção de todo o Complexo Prisional, que corresponde à construção de sete unidades prisionais, seria economizado $\mathrm{R} \$ 706.898,09$ de gastos desnecessários, que seriam utilizados apenas para cobrir custos de retrabalho e horas paradas de equipes devido a incompatibilidade entre os projetos.

Tabela 1 - Custos da análise custo-benefício.

\begin{tabular}{|l|l|}
\hline Classe da Interferência & Custos Potenciais \\
\hline Solucionável em obra - sem custo & $\mathrm{R} \$ 0,00$ \\
\hline Solucionável em obra - com custo & $\mathrm{R} \$ 51.857,85$ \\
\hline Revisão de projeto & $\mathrm{R} \$ 41.385,98$ \\
\hline Revisão de projeto com custo de solução & $\mathrm{R} \$ 7.741,61$ \\
\hline
\end{tabular}

Fonte: Autores (2021). 
O valor do contrato de gerenciamento do Complexo Prisional de Araçoiaba foi licitado e contratado por cerca de $1 \%$ do custo de construção da obra. Deste valor, aproximadamente $\mathrm{R} \$ 900.000,00$ se referem as atividades de gerenciamento com uso do processo BIM. As atividades contratadas utilizando BIM consistiram em:

- Realização de modelagem BIM dos projetos das Unidades Prisionais de Araçoiaba, com execução da compatibilização das disciplinas de projetos e elaboração de relatório de detecção de conflitos (Clash Detection), denominados "Relatórios de Análise Crítica".

- Acompanhamento das modificações do modelo BIM e do cronograma físico-financeiro de cada um dos empreendimentos. Onde os cronogramas executivos devem ser elaborados pelas construtoras responsáveis pela execução das obras e analiados pela gerenciadora, que é responsável pela alimentação e atualização das informações no modelo BIM.

- Elaboração de relatório comparativo do planejamento BIM 4D, contendo imagens da simulação 4D conforme cronograma elaborado pela construtora, imagens da simulação 4D de acordo com o status em cada fase dos empreendimentos, utilizando fotos e imagens atualizadas semanalmente, além de análise crítica deste comparativo, incluindo um vídeo de comparação entre o planejado e o efetivamente realizado, com legenda de cores e datas de referência.

Desta forma, podemos concluir que apenas um terço das atividades realizadas se referem aos RACs que são responsáveis pelos benefícios avaliados neste trabalho. Assim, podemos concluir que temos um custo de $\mathrm{R} \$ 300.000,00$ para um benefício de $\mathrm{R} \$ 706.898,09$, resultado em uma relação custo-benefício de 2,36.

Cabe ressaltar, ainda, que neste estudo foram levantados apenas as interferências estruturais, restringindo o processo, tendo-se analisado os custos que seriam causados por apenas 249 interferências, mas as interferências totalizam 520 em diversas disciplinas. É plausível inferir que caso fossem consideradas todas as interferências entre as diferentes tipologias, o valor encontrado para a redução de custos proporcionada pela compatibilização de projetos ainda na fase de projetos aumentaria. Salienta-se que foram desconsiderados, também, os custos relacionados ao chamado efeito dominó na construção civil. Ou seja, calculou-se, apenas, os custos trazidos diretamente pelas interferências a determinados serviços. O impacto do atraso desses serviços nas demais atividades da obra não foram considerados. Além destes, foram desconsiderados os custos trazidos pelo atraso na conclusão dos serviços referentes a administração da obra e instalações provisórias.

\section{Considerações Finais}

O presente trabalho teve como objetivo realizar uma análise custo-benefício em um estudo de caso de compatibilização de projetos através da criação de um modelo federado em uma obra de grande porte desenvolvida no estado de Pernambuco. Através da identificação de interferências entre projetos, obtidas mediante o uso do BIM para a compatibilização de projetos e elaboração de Relatórios de Análise Crítica para comunicação com os projetistas, foi possível quantificar os custos que incorreriam para o Governo Federal caso esta análise não houvesse sido realizada durante a fase de desenvolvimento dos projetos, a fim de compará-los com o investimento realizado pelo Governo Federal na contratação da equipe de gerenciamento para analisar se o investimento neste contrato era justificável.

As interferências encontradas, se identificadas apenas na fase de execução da edificação, acarretariam problemas estéticos, retrabalho, custos adicionais, além de atrasos no cronograma, onerando a obra em pelo menos $0,50 \%$ de seu valor total. Salienta-se, no entanto, que estes custos foram quantificados como redução de custos proporcionados pela compatibilização de projetos e foram considerados os custos com a equipe especializada de desenvolvimento da técnica, softwares utilizados e treinamento da equipe. 
Devido aos fatores de redução de escopo impostos, infere-se que a parcela de redução de custos acarretada pela compatibilização de projetos atrelada ao BIM tende a ser maior do que o obtido nesse estudo de caso, se considerados todos os custos que não foram calculados, gerando uma relação custo-benefício ainda superior aos 2,36 calculados neste estudo.

Uma das questões que se coloca quanto a adoção do BIM é que o Proprietário ou Cliente tem uma posição fundamental no processo de definição do escopo do que deve ser desenvolvido em projetos que adotam este processo, ocupando uma posição de liderança. Entretanto, a maioria dos proprietários contrata o desenvolvimento de poucos projetos de construção durante a vida útil da organização, não criando nenhum benchmarking neste sentido. Uma das questões atreladas a dificuldade dos Proprietários liderarem este processo é a falta de conhecimento técnico na área de AEC, mas também a ausência de valores que os auxiliem a comparar os custos de investimento com os possíveis ganhos gerados pelo uso deste processo. Alguns artigos apontam ganhos durante a vida útil da construção, como ganhos realizados através de simulações energéticas ou de uso da edificação. Entretanto, a fase mais elementar do uso deste processo não havia sido ainda quantificada, uma vez que seria preciso verificar quais custos onerariam o Proprietário durante a construção. Sendo assim, esse estudo de caso vem corroborar com os estudos realizados acerca do tema, demonstrando, quantitativamente, uma das vantagens do uso do BIM para a obtenção de projetos mais eficientes, reduzindo custos, aumentando a assertividade dos cronogramas além de possibilitar o desenvolvimento e finalização dos As Builts mais cedo e fidedignos a realidade das edificações.

Este estudo não teve um caráter prescritivo, mas de quantificar e corroborar com as percepções dos praticantes de BIM de que seu uso gera uma redução do custo geral da obra, contribuindo para a literatura ao confirmar e calcular essa redução através do estudo de caso. Em trabalhos futuros se espera quantificar a redução dos custos totais da obra, incluindo todas as interferências encontradas, entre todas as tipologias construtivas, identificar interferências entre elementos que ultrapassam tolerâncias geométricas de outros objetos, e quantificar a redução de custos proporcionada pela verificação desse tipo de conflito na fase de projeto e não apenas na fase de execução. Espera-se também comparar a compatibilização e a verificação de não conformidades em um sistema de projeção bidimensional (2D) e na modelagem tridimensional (3D), envolvendo, inclusive, custos associados à especialização das equipes, além de quantificar a redução de custos em outras obras, de diferentes portes, de forma a identificar a existência, ou não, de percentual constante na redução de custos proporcionada pelo uso da compatibilização de projetos atrelada ao BIM. Uma vez que pode haver discordância entre especialistas na definição dos custos decorridos das interferência e dos custos das atividades decorrente com BIM, em trabalhos futuros deverá ser realizada uma pesquisa com especialistas para definir estes custos, com o método Delphi, o que permitirá uma maior consistência no que tange aos resultados quantitativos obtidos.

\section{Referências}

Abd, A. M., \& Khamees, A. S. (2017). As built case studies for BIM as conflicts detection and documentation tool. Cogent Engineering, 4(1), 1-11. doi: $10.1080 / 23311916.2017 .1411865$

Akponeware, A. O., \& Adamu, Z. A. (2017). Clash Detection or Clash Avoidance? An Investigation into Coordination Problems in 3D BIM. Buildings, 7(3), 75. doi: 10.3390/buildings7030075

Bana e Costa, C. A., Oliveira, C. S., \& Vieira, V. (2008). Prioritization of bridges and tunnels in earthquake risk mitigation using multicriteria decision analysis: Application to Lisbon. Omega, 36(3), 442-450. doi: 10.1016/j.omega.2006.05.008

Barrocal, A., \& Pellegrini, M. (2015, March). Se cadeia resolvesse, o Brasil seria exemplar.

Berkes, F., \& Davidson-Hunt, I. J. (2007). Communities and social enterprises in the age of globalization. Journal of Enterprising Communities: People and Places in the Global Economy, 1(3), 209-221. doi: 10.1108/17506200710779521

Brasil. Decreto $n^{\circ}$ 7.983, de 08 de abril de 2013. Estabelece regras e critérios para elaboração do orçamento de referência de obras e serviços de engenharia, contratados e executados com recursos dos orçamentos da União, e dá outras providências., Pub. L. No. Decreto No 7.983 , de 8 de Abril de 2013 (2013). Brasil.

Brito, D. M. De, \& Ferreira, E. de A. M. (2015). Avaliação de estratégias para representação e análise do planejamento e controle de obras utilizando modelos BIM 4D. Ambiente Construído, 15(4), 203-223. doi: 10.1590/s1678-86212015000400047 
Bryde, D., Broquetas, M., \& Volm, J. M. (2013). The project benefits of building information modelling (BIM). International Journal of Project Management, 31(7), 971-980. doi: 10.1016/j.ijproman.2012.12.001

Carmona, F. V. F., Carvalho, M. T. M., Carmona, F. V. F., \& Carvalho, M. T. M. (2017). Caracterização da utilização do BIM no Distrito Federal. Ambiente Construído, 17(4), 385-401. doi: 10.1590/s1678-86212017000400203

Coutinho, A. B., Moura, G. S., \& Teixeira, E. K. da C. (2021). Compatibilização de um projeto arquitetônico e hidrossanitário utilizando a metodologia BIM. Research, Society and Development, 10(2), e58610212924. doi: 10.33448/rsd-v10i2.12924

Dantas Filho, J. B. P., Barros Neto, J. de P., \& Angelim, B. M. (2017). Mapeamento do fluxo de valor de processo de construção virtual baseado em BIM. Ambiente Construído, 17(4), 343-358. doi: 10.1590/s1678-86212017000400201

Gholizadeh, P., Esmaeili, B., \& Goodrum, P. (2018). Diffusion of Building Information Modeling Functions in the Construction Industry. Journal of Management in Engineering, 34(2), 04017060. doi: 10.1061/(ASCE)ME.1943-5479.0000589

Hamdi, O., \& Leite, F. (2014). Conflicting Side of Building Information Modeling Implementation in the Construction Industry. Journal of Legal Affairs and Dispute Resolution in Engineering and Construction, 6(3), 03013004. doi: 10.1061/(ASCE)LA.1943-4170.0000137

Jacobsson, M., \& Merschbrock, C. (2018). BIM coordinators: a review. Engineering, Construction and Architectural Management, 25(8), 989-1008. doi: 10.1108/ECAM-03-2017-0050

Liesiö, J., Mild, P., \& Salo, A. (2008). Robust portfolio modeling with incomplete cost information and project interdependencies. European Journal of Operational Research, 190(3), 679-695. doi: 10.1016/j.ejor.2007.06.049

Machado, E. L., Sotsek, N. C., Scheer, S., \& Santos, A. D. P. L. (2018). Seleção de sistemas construtivos utilizando BIM e método de tomada de decisão multicritério. Revista ALCONPAT, 8(2), 209. doi: 10.21041/ra.v8i2.246

Mechler, R. (2016). Reviewing estimates of the economic efficiency of disaster risk management: opportunities and limitations of using risk-based cost-benefit analysis. Natural Hazards, 81(3), 2121-2147. doi: 10.1007/s11069-016-2170-y

Mesároš, P., \& Mandičák, T. (2017). Exploitation and Benefits of BIM in Construction Project Management. IOP Conference Series: Materials Science and Engineering, 245(6). doi: 10.1088/1757-899X/245/6/062056

Novaes, C. C. (2001). Ações para controle e garantia da qualidade de projetos na construção de edifício. Workshop Nacional Gestão Do Processo De Projeto Na Construção De Edifícios, (16), 5.

Oberlender, G. D. (2014). Project management for engineering and construction (Third Edit). New York: McGraw-Hill Education.

Oesterreich, T. D., \& Teuteberg, F. (2018). Looking at the big picture of IS investment appraisal through the lens of systems theory: A System Dynamics approach for understanding the economic impact of BIM. Computers in Industry, 99(April), 262-281. doi: https://doi.org/10.1016/j.compind.2018.03.029

Pärn, E. A., Edwards, D. J., \& Sing, M. C. P. (2018). Origins and probabilities of MEP and structural design clashes within a federated BIM model. Automation in Construction, 85(November 2017), 209-219. doi: 10.1016/j.autcon.2017.09.010

Ruschel, R. C., Andrade, M. L. V. X. de, \& Morais, M. de. (2013). O ensino de BIM no Brasil: onde estamos? Ambiente Construído, 13(2), 151-165. doi: $10.1590 /$ S1678-86212013000200012

Sacks, R., Eastman, C., Lee, G., \& Teicholz, P. (2018). BIM Handbook (Third Edit). Hoboken, NJ, USA: John Wiley \& Sons, Inc. doi: 10.1002/9780470261309

Santos, D. M., \& Piacente, F. J. (2021). Indústria 4.0: Building Information Modelling no Custo de Construção Pública. Research, Society and Development, 10(1), e25210111681. doi: 10.33448/rsd-v10i1.11681

Santos, D. M., Piacente, F. J., Neves, J. M. S. das, \& Azevedo, M. M. de. (2021). Estudo comparativo da implementação da Modelagem da Informação da construção em obras públicas no Brasil e no Reino Unido. Research, Society and Development, 10(1), e25310111686. doi: 10.33448/rsd-v10i1.11686

SDSCJ. (2014). Pedra Fundamental inicia obras do Complexo Prisional de Araçoiaba.

Selçuk Çıdık, M., Boyd, D., \& Thurairajah, N. (2017). Innovative Capability of Building Information Modeling in Construction Design. Journal of Construction Engineering and Management, 143(8), 04017047. doi: 10.1061/(ASCE)CO.1943-7862.0001337

Simon, H. A. (1982). Models of Bounded Rationality (Economic A). Cambridge, MA: MIT Press.

Velasco, C., D’Agostino, R., \& Reis, T. (2017, January). AM supera PE e lidera ranking de superlotação em presídios; Brasil tem 270 mil presos acima da capacidade. Portal G1.

Wesz, J. G. B., Formoso, C. T., \& Tzortzopoulos, P. (2018). Planning and controlling design in engineered-to-order prefabricated building systems. Engineering, Construction and Architectural Management, 25(2), 134-152. doi: 10.1108/ECAM-02-2016-0045

Yin, R. K. (2014). Case Study Research Design and Methods (5th Editio). Thousand Oaks, CA: Sage. 